\title{
Health Personnel's Knowledge, Attitudes, and Self-Efficacy Related to Providing Palliative Care in Persons with Chronic Diseases
}

\author{
EunSeok Cha, Ph.D., Sojung Lee, Ph.D.*, Jooseon Lee, M.S. ${ }^{+{ }^{\ddagger}}$ and Insil Lee, Ph.D. \\ College of Nursing, Chungnam National University, Daejeon, "Department of Nursing, \\ Korean Bible University, Seoul, ${ }^{\dagger}$ Department of Public Health, Chungnam National University Hospital, \\ ${ }^{\ddagger}$ College of Nursing, Chungnam National University, Daejeon, Korea
}

Purpose: The purpose of this study was to examine the relationships of knowledge, at ${ }^{-}$ titudes, and self-efficacy related to palliative care among health care providers (doctors and nurses) in order to provide a basis to develop a training program for health care providers. Methods: A correlational and descriptive study design was used. Participants were recruited from a university-affiliated hospital located in Daejeon and an e-nurse community. After IRB approval, data were collected from July 12, 2018, to September 30, 2018. A total of 169 responses were finally analyzed using version SPSS 24 . The data were analyzed in terms of descriptive statistics (frequency and percentage or mean and standard deviation, as appropriate), the t-test, analysis of variance (with the Duncan post hoc test), and Pearson correlation coefficients. Results: Knowledge, attitudes, and self-efficacy were significantly higher in those who had received palliative care training or had been exposed to awarenessraising initiatives. There were positive relationships among knowledge, attitudes, and selfefficacy, with small to moderate effect sizes. Conclusion: Palliative care training for health care professionals is necessary to meet patients' needs. Such programs should take into account not only knowledge about palliative care, but also ways to improve empathy and resolve ethical dilemmas. Interprofessional training would be an excellent option to share therapeutic goals and develop communication skills among multidisciplinary team members.

Key Words: Chronic disease, Palliative care, Health personnel
Received April 29, 2020

Revised September 25, 2020

Accepted October 2, 2020

\author{
Correspondence to \\ Sojung Lee \\ ORCID: \\ https://orcid.org/0000-0002-0057-4114 \\ E-mail: fate71@bible.ac.kr \\ This research was supported by the \\ National Research Foundation of Korea \\ (NRF-2017R1D1A3B03035133, NRF- \\ 2019R1A2C108719912).
}

\section{INTRODUCTION}

\section{Background}

State-of-the-art science and advanced medical technology have enabled life extension to a degree that was not possible in the past. However, failing to consider the patient's choice and quality of life when making decisions about life-sustaining treatment is tantamount to depriving the patient of his or her right to death with dignity as a human being, and also places a financial burden on the family due to the high medical costs and psychological stress associated with long-term, unending caregiving and exposes the medical staff to legal, psychological, and ethical dilemmas [1].

Palliative care is a professional health care service aimed at relieving the physical, psychological, social, and spiritual dis-

This is an Open Access article distributed under the terms of the Creative Commons Attribution Non-Commercial License (http://creativecommons.org/licenses/by-nc/4.0/) which permits unrestricted non-commercial use, distribution, and reproduction in any medium, provided the original work is properly cited. 
tress of patients with intractable diseases and their families by providing medical interventions for symptom and pain relief, information on treatment options, support, and welfare services [2,3]. Palliative care helps to reduce anxiety regarding disease-related pain and death and may allow patients to make the most of the rest of their life [2,3]. In Korea, the term "palliative care" has been used interchangeably with "hospice care" or "end-of-life care", and has been provided mainly to patients at the end of life in the dying process or with terminal cancers, whereas in many advanced countries, including the US, palliative care is subdivided into three levels and is also offered to patients with advanced chronic diseases and their family members [2-4].

Primary palliative care refers to providing information on the status and progression of a disease to patients with intractable diseases and their families, guidance on community resources or services available in the event of exacerbation, and education on the need to carry out advance care planning so that patients and their families can proactively prepare for the painful family event that they will experience in the future [2]. That is, primary palliative care includes the provision of education and services to help patients make medical treatment decisions in advance (including life-sustaining treatment), improve their spiritual well-being, and "prepare for the end of life on [their] own terms" [2]. Secondary palliative care is a team-based service provided by a team of health care providers in various environments, including residential facilities, nursing homes, and outpatient clinics, to improve the physical, mental, social, and spiritual health of patients and their families [3]. This health care service may be included as part of community care, which the Korean government is keen on establishing. Secondary palliative care encompasses exploring local resources to improve the quality of life of patients and their families and establishing targeted care coordination to deliver organized health care, nursing, and welfare services, as well as providing medical service, treatment, and nursing to relieve patients' pain and symptoms [3]. Tertiary palliative care consists of nursing for pain relief (i.e., management of pain and symptoms in extremely stressful situations that threaten physical, mental, social, and spiritual health), reducing fear of death, and supporting bereaved families [3,5]. Hospice care and end-of-life palliative care, which are currently provided in Korea for terminally ill, dying, and cancer patients, are forms of tertiary palliative care.

Despite the recognition of the need to provide palliative care to patients with advanced chronic diseases, health professionals may be hesitant to do so due to the absence of palliative care protocols for chronic disease patients [6], limited experience of receiving palliative care education [7], and the difficulty of determining when to discuss preparation for death, as the prognosis (direction, speed, etc.) of chronic diseases is relatively unpredictable, unlike that of terminal cancers [6]. Furthermore, medical professionals tend to consider death solely as the result of diagnostic misclassification or failure of the prescribed treatment [8]. In particular, young health personnel often regard death as a challenge to overcome as a human being, which may be another major reason behind their hesitation [9].

According to the Annual Report on the Life-Sustaining Decision-Making System of the Korea National Institute for Bioethics Policy [10], since the passage of the Act on Decisions on Life-Sustaining Treatment, the number of adults (age 19 years or over) with an advance directive increased 10-fold from 7,637 in 2017 to 93,395 in 2018. More women (67.5\%) than men (32.5\%) had advance directives, and their age ranged from 20 years to nearly 100 years. The largest number of people were in their 70 s $(43.4 \%)$, followed by other older age groups, including those in their 60s (23.4\%), 80s (17.2\%), and 90 s $(0.8 \%)$. Although the senior age groups accounted for the largest proportion of adults with advance directives, some adults in younger age groups, including those in their $20 s \sim 50$ s, were also found to have advance directives $(10.4 \%$, $3.6 \%, 0.8 \%$, and $0.4 \%$ of those in their $50 \mathrm{~s}, 40 \mathrm{~s}, 30 \mathrm{~s}$, and $20 \mathrm{~s}$, respectively). The largest proportion of people with advance directives was found to reside in Seoul (26.3\%). The registration rates were much higher at community institutions such as public institutions (50.8\%), non-profit corporations or organizations (30.0\%), and local health care clinics (8.3\%) than at medical institutions (10.8\%). This underscores the need for medical professionals to understand the needs of communitydwelling chronic disease patients near the end of life, who wish to maintain their dignity and quality of life until the moment of death while reducing burdens on their families, as well as providing hospice palliative care for hospitalized terminally ill 
patients [11] and building capacity to provide and support appropriate palliative care (e.g., primary palliative care).

This study was conducted under the hypothesis that accurate and up-to-date knowledge of palliative care among health personnel would help them cultivate a positive attitude and enhance self-efficacy in the provision of palliative care to $\mathrm{pa}^{-}$ tients with chronic diseases other than cancer nearing the end of life. The results of this study will be used as basic data for developing health professional education on the provision of primary palliative care to patients with advanced chronic diseases.

\section{Purpose}

The purpose of this study was to obtain basic data for developing programs to train health personnel to provide primary palliative care to community-dwelling patients with advanced chronic diseases other than cancer. In this study, we investigated health personnel's knowledge, attitude, and self-efficacy related to plans that help patients determine treatment decisions (referred to "advance care planning" in this study to distinguish it from "advance directives", which are implemented under the Act on Decisions on Life-Sustaining Treatment). The specific objectives were as follows:

1) To determine health personnel's knowledge, attitude, and self-efficacy related to palliative care according to sociodemographic characteristics.

2) To compare health personnel's knowledge, attitude, and self-efficacy related to palliative care according to their responses to specific questions.

3) To compare health personnel's knowledge, attitude, and self-efficacy according to their experience in palliative care.

4) To identify correlations between health personnel's knowledge of palliative care, attitude, and self-efficacy.

\section{METHODS}

\section{Study design}

This descriptive study was designed to identify the levels of and correlations between health personnel's knowledge, attitudes, and self-efficacy related to advance care planning (primary palliative care), which helps patients with chronic diseases make treatment decisions in advance.

\section{Study participants}

The study participants were health personnel (physicians and nurses) who were engaged in or expected to provide palliative care to patients with chronic diseases. An appropriate sample size was calculated using $G^{*}$ Power version 3.0.10. The power analysis was set at $80 \%$ with Cohen's $r=0.23$ (a small to medium effect), an alpha of 0.05 (two-tailed), and a population correction $(\rho)$ of 0 . The calculated sample size was 146 , but we recruited 186 participants, considering a possible dropout rate of approximately $25 \%$.

\section{Research tool}

Due to the absence of prior research on advance care planning for patients with advanced chronic disease and a standardized questionnaire, the first author developed a preliminary draft questionnaire based on prior studies on hospice care for the elderly or terminally ill patients and discussions with professionals who provide life-sustaining treatment in clinical settings (physicians, nurses, and social workers). The research team sought feedback from a group of three experts (one physician and two nurses) in two separate sessions to confirm the construct validity of the research tool [12]. Furthermore, face validity was verified by undergraduates and graduate nursing students. The survey questionnaires consisted of: 1) sociodemographic characteristics and palliative care experience and 2) knowledge related to advance care planning, attitudes toward advance care planning, and self-efficacy related to the discussion of advance care planning.

\section{1) Sociodemographic characteristics and palliative care experience}

In this section, there were nine questions on sociodemographic characteristics and nine questions on palliative care experience. The questions included whether participants had experienced situations in which family members or close acquaintances had experienced or died from cancer or noncancerous diseases, whether they had received education or been exposed to awareness-raising initiatives regarding lifesustaining treatment, and whether they had heard of advance directives or advance care planning. Referring to the question- 
naire developed by Jezewski et al. [13] and revised by Kim [14], we devised a questionnaire including additional questions on the study participants' experiences of providing palliative care to patients with cancer or non-cancerous diseases or to their family members, such as explaining policies or procedures related to advance directives or advance care planning, discussing how to carry out advance care planning, and offering care.

\section{2) Knowledge, attitudes, and self-efficacy of health per- sonnel related to providing palliative care}

Health personnel's knowledge, attitudes, and self-efficacy regarding the provision of palliative care were assessed in terms of their knowledge of advance care planning, their attitudes toward advance care planning, and their self-efficacy related to discussions about advance care planning.

\section{(1) Knowledge of advance care planning}

Health personnel's knowledge of the provision of palliative care was assessed with a 15-item questionnaire developed by the first author, referring to a questionnaire devised by Hong and Kim [15] to evaluate the level of knowledge of treatment in the dying process, life-sustaining treatment, and advance directives for elderly living in a community. The preliminary draft consisted of 15 knowledge assessment questions, including nine of 10 questions from Hong and Kim's questionnaire and six questions added by the author. Based on the first round of feedback from three experts, two questions were integrated into one and one question was added to the questionnaire. Subsequently, upon receiving the second round of feedback, the research team revised seven questions and finalized the 15-item questionnaire. Considering the purpose of the study, we focused on providing the medical information required for life-sustaining treatment and advance care planning for patients with advanced chronic diseases and added questions on knowledge related to the Act on Decisions on LifeSustaining Treatment. The highest score of the questionnaire was 15 points, with 1 point awarded for the correct answer and 0 points for an incorrect answer. The Kuder-Richardson 20 coefficient for the reliability of the research tool was 0.612 .

\section{(2) Attitudes toward advance care planning}

Health personnel's attitudes toward the provision of pallia- tive care were assessed by a 14-item questionnaire, which was developed by the first author by referring to the questionnaire developed by Jezewski et al. [13] and modified by Kim [14] and taking into account the implementation of the Act on $\mathrm{De}^{-}$ cisions on Life-Sustaining Treatment in 2018. In the original questionnaire, 20 questions were asked about attitudes toward advance directives and end-of-life issues; however, the research team utilized only nine questions that were considered appropriate, as the current study was intended for patients near the end of life, not at the end of life. Subsequently, based on the first round of feedback from three experts, the draft questionnaire was revised to include 10 questions by adding one question and modifying four questions. Based on the second round of expert review, five questions were added and one similar question was deleted, leading to a 14 -item questionnaire. The answers were rated using a 4-point Likert scale, ranging from "not at all desirable" (1 point) to "very desirable" (4 points). Higher scores indicated more desirable attitudes. The reliability of the questionnaire as a research tool assessed using the Cronbach's $\alpha$ coefficient was 0.867 .

\section{(3) Self-efficacy related to discussions about advance care planning}

The self-efficacy of health personnel for the provision of palliative care was assessed using a questionnaire developed by the first author by referring to the self-efficacy questionnaire devised by Jezewski et al. [13] and modified by Kim and Kim [14]. The draft questionnaire consisted of 30 questions, and was formulated based on the results of interviews conducted by the researcher on perceptions of advance care planning among patients with chronic diseases other than cancer [16] and 11 items consisting of a 5-point scale included in the original tool. Referring to the first round of review by three experts, we modified the content and adopted a 4-point scale. Upon receiving the second round of feedback, we deleted 10 questions related to advance directives. Thus, the final version of the questionnaire included 20 questions, which were scored from 1 point for "not at all confident" to 4 points for "very confident". Higher scores indicated higher self-efficacy. The Cronbach's $\alpha$ coefficient for the reliability of the research tool was 0.977 . 


\section{Data collection and data analysis}

The data collection period was approximately 3 months, from July 12, 2018 to September 30, 2018. The study was approved by the Institutional Ethics Committee of Chungnam National University, the College of Nursing (201804-SB-04701 , and the participants were recruited with the permission of a University Hospital and the cooperation of the relevant department head. For data collection, questionnaires with a consent form and a study purpose description form attached were distributed and completed questionnaires were collected from a collection box by the researchers, or the researchers explained the purpose of the study in person during a medical training session and requested cooperation in data collection.

The collected data were analyzed using SPSS version 24 (IBM Corp., Armonk, NY, USA). Of the total of 186 questionnaires that were collected, uncompleted ones were excluded from the analysis, including six responses with $80 \%$ of the questions on the knowledge, attitudes, and self-efficacy not answered and 11 questionnaires with many incomplete answers on sociodemographic characteristics. Using listwise deletion, we included data with one or two variables missing in the analysis; thus, the total number of questionnaires included in the final analysis was 169 .

The general characteristics of the study participants are presented as frequency and percentage, and the levels of health personnel's knowledge, attitudes, and self-efficacy related to providing palliative care are presented using descriptive statistics. Differences in health personnel's knowledge, attitudes, and self-efficacy according to general characteristics were analyzed using the $\mathrm{t}$-test and analysis of variance (with the Duncan test for post hoc analysis). Correlations between variables were analyzed using Pearson correlation coefficients.

\section{RESULTS}

\section{Sociodemographic characteristics of participants}

The sociodemographic characteristics of the participants are shown in Table 1. There were 117 (69.2\%) nurses and 52 (30.8\%) physicians, $136(80.5 \%)$ participants were women, 87 (51.5\%) had a 4-year college bachelor's degree, and 63 (37.3
Table 1. Participants' Socio-Demographic Characteristics (N=169).

\begin{tabular}{|c|c|c|}
\hline Category & Item & $\mathrm{n}(\%)$ \\
\hline \multirow[t]{3}{*}{ Gender } & Male & $32(18.9)$ \\
\hline & Female & $136(80.5)$ \\
\hline & Missing data & $1(0.6)$ \\
\hline \multirow[t]{2}{*}{ Profession } & Nurse & $117(69.2)$ \\
\hline & Doctor & $52(30.8)$ \\
\hline \multirow[t]{5}{*}{ Age (yr) } & Less than 30 & $63(37.3)$ \\
\hline & $30 \sim 35$ & $48(28.4)$ \\
\hline & $35 \sim 40$ & $25(14.8)$ \\
\hline & More than 40 & $27(16.0)$ \\
\hline & Missing data & $6(3.6)$ \\
\hline \multirow[t]{5}{*}{ Career (yr) } & Less than 1 & $32(18.9)$ \\
\hline & $1 \sim 5$ & $90(53.3)$ \\
\hline & $5 \sim 10$ & $23(13.6)$ \\
\hline & More than 10 & $16(9.5)$ \\
\hline & Missing data & $8(4.7)$ \\
\hline \multirow[t]{7}{*}{ Department } & Internal medicine & $61(36.1)$ \\
\hline & Neurology & $10(5.9)$ \\
\hline & Hospice & $6(3.6)$ \\
\hline & Rehabilitation & $27(16.0)$ \\
\hline & Surgery & $20(11.8)$ \\
\hline & ICU, ED, anesthesiology & $7(4.1)$ \\
\hline & Others & $38(22.4)$ \\
\hline \multirow[t]{4}{*}{ Education } & 2- or 3-year college & $15(8.9)$ \\
\hline & 4-year college & $87(51.4)$ \\
\hline & $\geq$ Master's degree & $63(37.3)$ \\
\hline & Missing data & $4(2.4)$ \\
\hline \multirow[t]{4}{*}{ Religion } & Protestantism & $51(30.2)$ \\
\hline & Buddhism & $15(8.9)$ \\
\hline & Catholicism & $19(11.2)$ \\
\hline & None or others & $84(49.7)$ \\
\hline \multirow[t]{2}{*}{ Marital status } & Single & $110(65.1)$ \\
\hline & Married & $59(34.9)$ \\
\hline \multirow[t]{2}{*}{ Having children } & No & $130(76.9)$ \\
\hline & Yes & $39(23.1)$ \\
\hline
\end{tabular}

ICU: intensive care unit, ED: emergency department.

$\%)$ had a master's or higher degree. The number of participants aged 24 to 34 years was 111 (65.7\%), and $122(72.2 \%)$ had 5 years or less of clinical experience. The largest number of participants worked in the department of internal medicine $(n=61,36.4 \%)$, followed by rehabilitation $(n=27,16.0 \%)$, surgery $(n=20,11.8 \%)$, neurology $(n=10,5.9 \%)$, intensive care unit/emergency department/anesthesiology $(n=7,4.1 \%)$, and hospice care $(n=6,3.6 \%)$. Fifty-nine people (34.9\%) were married and 39 (23.1\%) had children. 


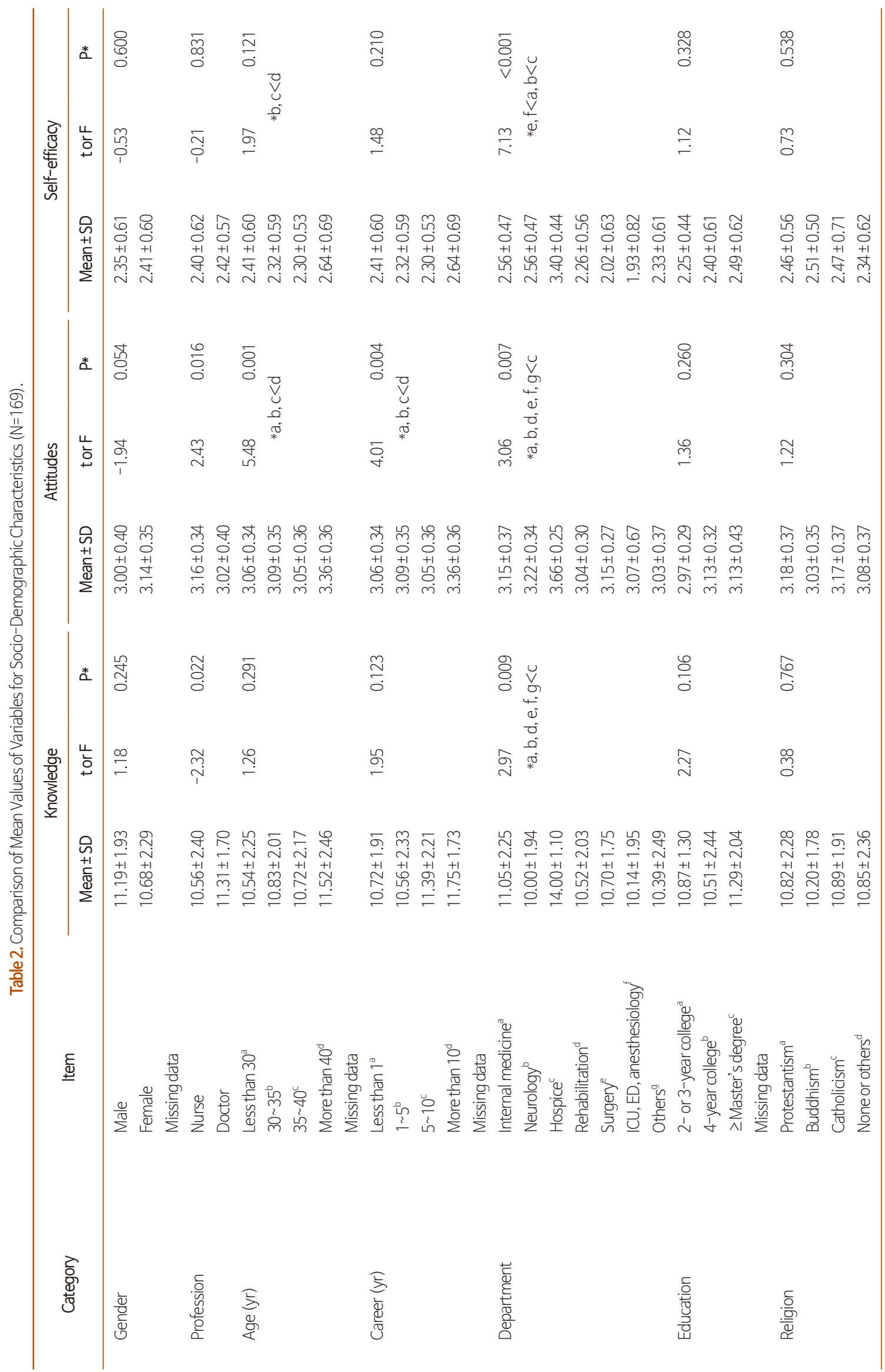




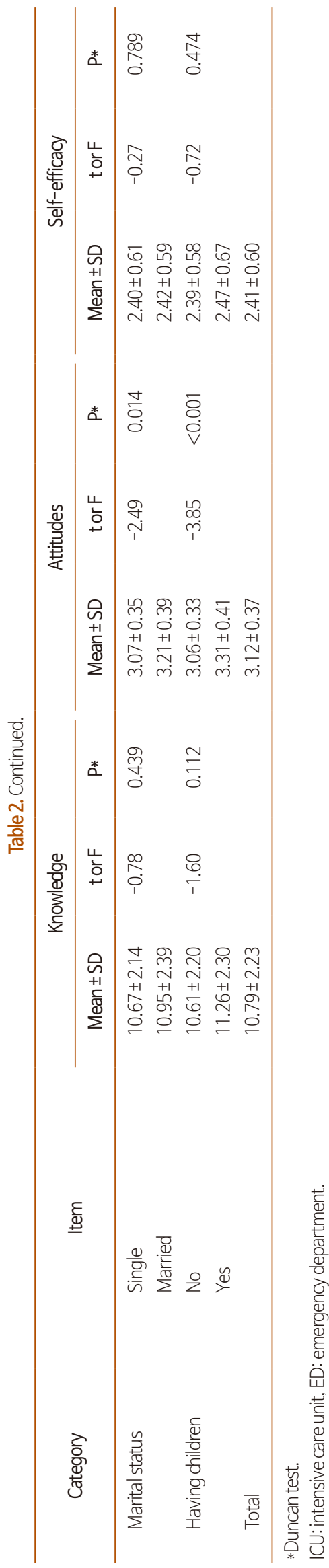

\section{Comparison of health personnel's knowledge, attitudes, and self-efficacy related to providing palliative care according to sociodemographic characteristics}

Table 2 shows differences in health personnel's knowledge, attitudes, and self-efficacy related to providing palliative care according to their sociodemographic characteristics.

The average score for knowledge related to advance care planning was $10.79 \pm 2.23$ points among all participants. The average score was significantly higher among physicians than among nurses $(t=-2.32, P=0.022)$ and for those working in the hospice department than for those working in other departments $(\mathrm{F}=2.97$ and $\mathrm{P}=0.009$ ).

The average score for attitudes toward advance care planning was $3.12 \pm 0.37$ points. The average score was significantly higher among nurses than among physicians $(\mathrm{t}=2.43$, $\mathrm{P}=0.016$ ). In the Duncan post hoc analysis, the scores were significantly higher among those who were more than 40 years of age than among those who were less than 40 years old $(\mathrm{F}=5.48, \mathrm{P}=0.001)$, among those who had more than 10 years of work experience than among those with less than 10 years of experience $(\mathrm{F}=4.01, \mathrm{P}=0.004)$, and among those who worked in the hospice department than among those who worked in other departments $(\mathrm{F}=3.06, \mathrm{P}=0.007)$. In addition, participants who were married $(\mathrm{t}=-2.49, \mathrm{P}=0.014)$ or had children $(\mathrm{t}=-3.85$ and $\mathrm{P}<0.001)$ had significantly higher scores.

Health personnel's self-efficacy averaged $2.41 \pm 0.60$ points, with no significant difference between professions; the only significant differences were found between departments $(\mathrm{F}=7.13, \mathrm{P}<0.001)$. The average score was significantly higher among those who worked in the hospice department than among those who worked in internal medicine and neurology, and personnel working in the latter two departments had significantly higher scores than those working in rehabilitation, surgery, intensive care unit, the emergency department, and anesthesiology. 


\section{Comparison of health personnel's knowledge, at- titudes, and self-efficacy regarding palliative care by item}

Health personnel's knowledge, attitudes, and self-efficacy for the provision of palliative care by item were compared, as shown in Tables 3, 4, and 5.
The average rate of correct answers for questions related to health personnel's knowledge of palliative care was $71.9 \%$, with the highest proportion of participants (99.4\%) correctly stating that "A patient has the right to accept or refuse lifesustaining treatment". Meanwhile, the rates of correct answers were below 50\% for the following items: "A patient can ask a primary care provider to make an advance directive" (16.0\%)

Table 3. Scores on Knowledge Related to Advance Care Planning by Profession ( $N=169)$.

\begin{tabular}{|c|c|c|c|c|c|c|c|}
\hline \multirow{2}{*}{ Item } & \multicolumn{2}{|c|}{$\begin{array}{l}\text { Rate of correct } \\
\text { answers }\end{array}$} & \multicolumn{3}{|c|}{ Mean $\pm S D$} & \multirow{2}{*}{$\mathrm{t}$} & \multirow{2}{*}{$\mathrm{P}$} \\
\hline & $n$ & $\%$ & Total & Nurse & Doctor & & \\
\hline $\begin{array}{l}\text { 1. A patient has the right to accept or refuse life -sustaining } \\
\text { treatment }\end{array}$ & 168 & 99.4 & $0.99 \pm 0.08$ & $0.99 \pm 0.09$ & $1.00 \pm 0.00$ & -0.67 & 0.507 \\
\hline $\begin{array}{l}\text { 2. According to the Act on Decisions on Life-Sustaining } \\
\text { Treatment, CPR is within the scope of life-sustaining } \\
\text { treatment }\end{array}$ & 153 & 90.5 & $0.91 \pm 0.29$ & $0.87 \pm 0.34$ & $0.98 \pm 0.14$ & -2.98 & 0.003 \\
\hline $\begin{array}{l}\text { 3. According to the Act on Decisions on Life-Sustaining } \\
\text { Treatment, an artificial respirator is within the scope of } \\
\text { life-sustaining treatment }\end{array}$ & 150 & 88.8 & $0.89 \pm 0.32$ & $0.85 \pm 0.36$ & $0.98 \pm 0.14$ & -3.49 & 0.001 \\
\hline $\begin{array}{l}\text { 4. According to the Act on Decisions on Life-Sustaining } \\
\text { Treatment, anti-cancer treatment is within the scope of } \\
\text { life-sustaining treatment }\end{array}$ & 100 & 59.2 & $0.59 \pm 0.49$ & $0.61 \pm 0.49$ & $0.56 \pm 0.50$ & 0.60 & 0.551 \\
\hline $\begin{array}{l}\text { 5. According to the Act on Decisions on Life-Sustaining } \\
\text { Treatment, hemodialysis is within the scope of life- } \\
\text { sustaining treatment }\end{array}$ & 111 & 65.7 & $0.66 \pm 0.48$ & $0.68 \pm 0.47$ & $0.62 \pm 0.49$ & 0.75 & 0.453 \\
\hline $\begin{array}{l}\text { 6. Advance medical directives completed by an adult aged } \\
19 \text { or older are legally valid }\end{array}$ & 30 & 17.8 & $0.18 \pm 0.38$ & $0.19 \pm 0.39$ & $0.15 \pm 0.36$ & 0.53 & 0.594 \\
\hline 7. Advance medical directives never change once written & 146 & 86.4 & $0.86 \pm 0.34$ & $0.86 \pm 0.35$ & $0.87 \pm 0.34$ & -0.04 & 0.970 \\
\hline $\begin{array}{l}\text { 8. A patient can ask a primary health care provider to } \\
\text { complete an advance medical directive }\end{array}$ & 27 & 16.0 & $0.16 \pm 0.37$ & $0.15 \pm 0.35$ & $0.19 \pm 0.40$ & -0.77 & 0.444 \\
\hline $\begin{array}{l}\text { 9. Only advance medical directive completed by a lawyer } \\
\text { are legally valid }\end{array}$ & 107 & 63.3 & $0.63 \pm 0.48$ & $0.58 \pm 0.50$ & $0.75 \pm 0.44$ & -2.22 & 0.028 \\
\hline $\begin{array}{l}\text { 10. A patient in terminal care or death can complete a life- } \\
\text { sustaining treatment form }\end{array}$ & 155 & 91.7 & $0.92 \pm 0.27$ & $0.92 \pm 0.27$ & $0.92 \pm 0.27$ & -0.01 & 0.988 \\
\hline $\begin{array}{l}\text { 11. A chronically ill patient in a local community can complete } \\
\text { advance medical directive }\end{array}$ & 144 & 85.2 & $0.85 \pm 0.36$ & $0.84 \pm 0.37$ & $0.88 \pm 0.32$ & -0.79 & 0.430 \\
\hline $\begin{array}{l}\text { 12. Family members' agreement regarding the patient's } \\
\text { core values for life-sustaining treatment can be used to } \\
\text { determine a patient's intent for life-sustaining decision } \\
\text { making if an advance medical directive has not been } \\
\text { completed }\end{array}$ & 116 & 68.6 & $0.69 \pm 0.46$ & $0.65 \pm 0.48$ & $0.79 \pm 0.41$ & -1.96 & 0.053 \\
\hline $\begin{array}{l}\text { 13. An advance care plan is a document describing essential } \\
\text { medical actions for an ill patient incapable of making } \\
\text { decisions }\end{array}$ & 113 & 66.9 & $0.67 \pm 0.47$ & $0.62 \pm 0.49$ & $0.79 \pm 0.41$ & -2.30 & 0.023 \\
\hline $\begin{array}{l}\text { 14. A medical, or legal representative can make a health } \\
\text { care decision on behalf of a patient unable to speak on a } \\
\text { temporary or long term basis }\end{array}$ & 156 & 92.3 & $0.93 \pm 0.26$ & $0.92 \pm 0.27$ & $0.94 \pm 0.24$ & -0.46 & 0.646 \\
\hline $\begin{array}{l}\text { 15. A patient can change his or her medical, or legal } \\
\text { representative at any time }\end{array}$ & 147 & 87.0 & $0.88 \pm 0.33$ & $0.87 \pm 0.34$ & $0.88 \pm 0.32$ & -0.25 & 0.802 \\
\hline Sum of knowledge & & 71.9 & $10.79 \pm 2.23$ & $10.56 \pm 2.40$ & $11.31 \pm 1.70$ & -2.32 & 0.022 \\
\hline
\end{tabular}


Table 4. Mean Scores for Attitudes towards Advance Care Planning by Profession ( $N=169)$.

\begin{tabular}{|c|c|c|c|c|c|}
\hline \multirow{2}{*}{ Item } & \multicolumn{3}{|c|}{ Mean \pm SD } & \multirow{2}{*}{$\mathrm{t}$} & \multirow{2}{*}{$P$} \\
\hline & Total & Nurse & Doctor & & \\
\hline $\begin{array}{l}\text { 1. A patient at the end of life can make a decision and has a right to } \\
\text { refuse life-support devices in advance }\end{array}$ & $3.34 \pm 0.47$ & $3.38 \pm 0.49$ & $3.23 \pm 0.43$ & 2.07 & 0.041 \\
\hline $\begin{array}{l}\text { 2. A chronically ill patient can demand a life-support device in advance, } \\
\text { even if he/she is not at a stage of terminal care or end of life }\end{array}$ & $3.34 \pm 0.51$ & $3.38 \pm 0.51$ & $3.25 \pm 0.52$ & 1.58 & 0.115 \\
\hline $\begin{array}{l}\text { 3. Chronically ill patients have the right to make a preliminary decision } \\
\text { to refuse life-support devices }\end{array}$ & $3.33 \pm 0.56$ & $3.38 \pm 0.52$ & $3.19 \pm 0.63$ & 2.07 & 0.040 \\
\hline $\begin{array}{l}\text { 4. Everyone has a right to make a preliminary decision to refuse life- } \\
\text { support devices }\end{array}$ & $3.31 \pm 0.59$ & $3.38 \pm 0.55$ & $3.15 \pm 0.64$ & 2.38 & 0.018 \\
\hline $\begin{array}{l}\text { 5. A healthcare provider should respect the wishes of a patient despite } \\
\text { disagreement over end of life care decisions }\end{array}$ & $3.14 \pm 0.68$ & $3.24 \pm 0.60$ & $2.90 \pm 0.81$ & 3.02 & 0.003 \\
\hline 6. It may be best not to provide all information to the patient & $2.01 \pm 1.40$ & $2.03 \pm 1.40$ & $1.97 \pm 1.40$ & 0.20 & 0.842 \\
\hline $\begin{array}{l}\text { 7. If there is a conflict between the patient's and family's wishes for end } \\
\text { of life care decision, the nurse should follow the patient's opinion }\end{array}$ & $2.96 \pm 0.64$ & $3.05 \pm 0.54$ & $2.75 \pm 0.79$ & 2.51 & 0.014 \\
\hline $\begin{array}{l}\text { 8. All patients capable of making a decision should prepare advance } \\
\text { medical directives, and advance care planning }\end{array}$ & $3.14 \pm 0.55$ & $3.16 \pm 0.53$ & $3.10 \pm 0.60$ & 0.74 & 0.463 \\
\hline $\begin{array}{l}\text { 9. Nurses should actively assist patients in preparing advance medical } \\
\text { directives, advance care planning }\end{array}$ & $3.14 \pm 0.61$ & $3.11 \pm 0.64$ & $3.19 \pm 0.53$ & -0.79 & 0.431 \\
\hline $\begin{array}{l}\text { 10. If the primary doctor does not consider the patient's values regarding } \\
\text { 'death with dignity' as a treatment option, any other physicians } \\
\text { involved in patient care should provide information on life-sustaining } \\
\text { treatment }\end{array}$ & $3.04 \pm 0.57$ & $3.06 \pm 0.59$ & $2.98 \pm 0.50$ & 0.84 & 0.402 \\
\hline $\begin{array}{l}\text { 11. If the primary doctor does not consider the patient's values regarding } \\
\text { 'death with dignity' as a treatment option, nurses involved patient } \\
\text { care should provide information on life-sustaining treatment }\end{array}$ & $3.03 \pm 0.58$ & $3.06 \pm 0.58$ & $2.96 \pm 0.59$ & 1.01 & 0.312 \\
\hline $\begin{array}{l}\text { 12. If the primary doctor does not consider the patient's values regarding } \\
\text { 'death with dignity' as a treatment option, any person involved in } \\
\text { patient care (ex. social workers) should provide information on life- } \\
\text { sustaining treatment }\end{array}$ & $3.02 \pm 0.60$ & $3.09 \pm 0.56$ & $2.87 \pm 0.66$ & 2.18 & 0.032 \\
\hline $\begin{array}{l}\text { 13. Nurses should assist patients in deciding on life-sustaining } \\
\text { treatment, and its refusal or suspension should be presented as one } \\
\text { of the options for treatments }\end{array}$ & $3.17 \pm 0.43$ & $3.20 \pm 0.44$ & $3.10 \pm 0.41$ & 1.36 & 0.176 \\
\hline $\begin{array}{l}\text { 14. Nurses should have the ability to provide adequate information and } \\
\text { counseling to reassure patients and family members regarding life- } \\
\text { sustaining treatment }\end{array}$ & $3.27 \pm 0.47$ & $3.31 \pm 0.48$ & $3.18 \pm 0.43$ & 1.74 & 0.084 \\
\hline Total mean score & $3.12 \pm 0.37$ & $3.16 \pm 0.34$ & $3.02 \pm 0.40$ & 2.43 & 0.016 \\
\hline
\end{tabular}

Table 5. Mean Scores for Self-Efficacy Related to Advance Care Planning by Profession (N=169).

\begin{tabular}{lcccrr}
\hline \multirow{2}{*}{ Item } & \multicolumn{3}{c}{ Mean \pm SD } & t & D \\
\cline { 2 - 5 } & Total & Nurse & Doctor & \\
\hline Advance medical directives & $2.46 \pm 0.61$ & $2.44 \pm 0.61$ & $2.51 \pm 0.60$ & -0.67 & 0.501 \\
Advance care planning & $2.35 \pm 0.68$ & $2.36 \pm 0.69$ & $2.33 \pm 0.67$ & 0.22 & 0.828 \\
Total mean score & $2.41 \pm 0.60$ & $2.40 \pm 0.62$ & $2.42 \pm 0.57$ & -0.21 & 0.831 \\
\hline
\end{tabular}

and "An advance directive completed by an adult aged 19 years or older and kept in a drawer is legally valid" (17.8\%).

Among the questions on the health personnel's attitudes to- ward palliative care, the lowest score was found for "It may be best not to provide all information to the patient" $(2.01 \pm 1.40$ points), followed by "If there is a conflict between the patient' 


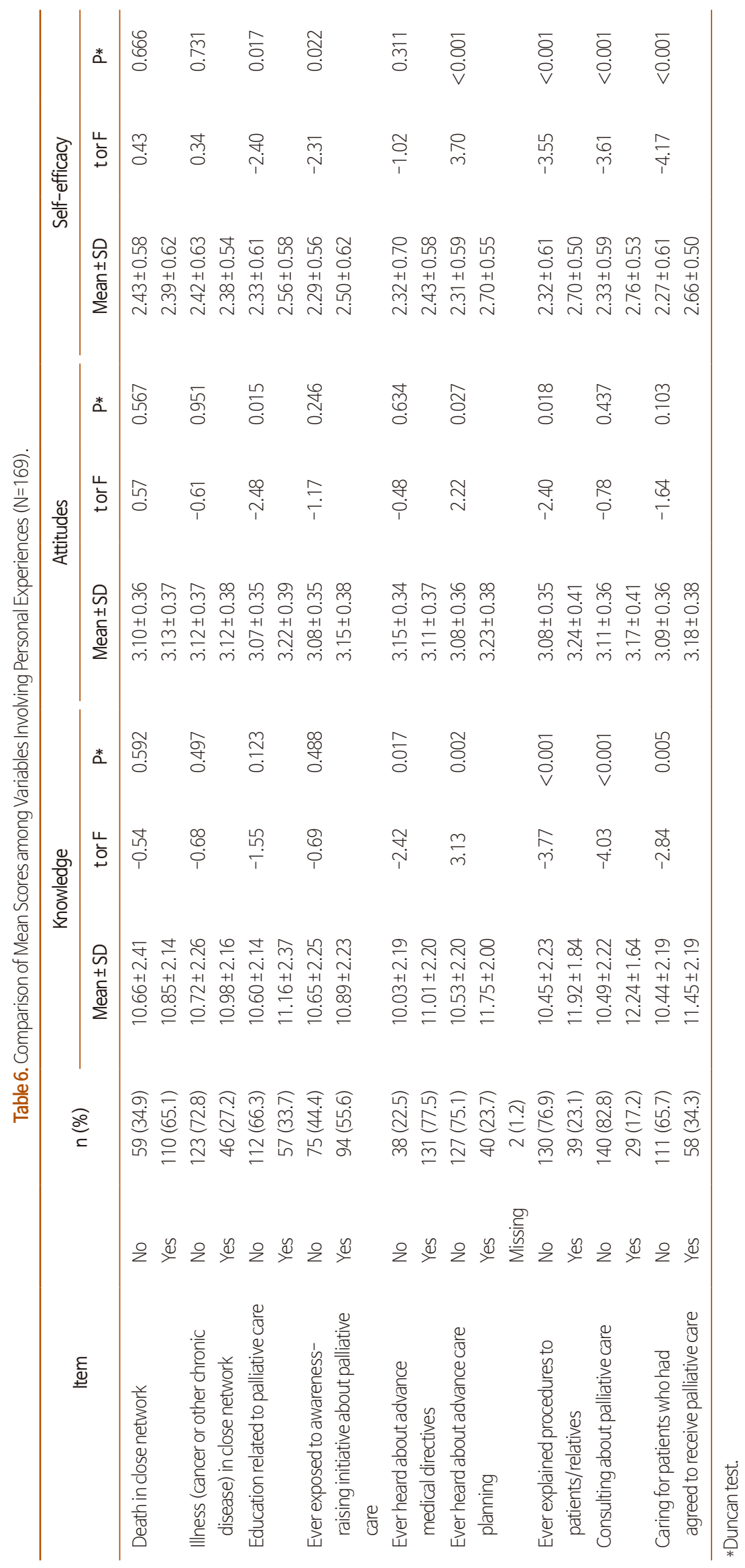


$s$ and family's wishes for end-of-life care decisions, the nurse should follow the patient's opinion" $2.96 \pm 0.64$ points) and "If the primary doctor does not consider the patient's values regarding 'death with dignity' as a treatment option, any person involved in patient care (ex. social workers) should provide information on life-sustaining treatment" (3.02 \pm 0.60 points) (Table 4).

Regarding the health personnel's self-efficacy for providing palliative care, the score for advance directives was $2.46 \pm 0.61$ points and the score for advance care planning was $2.35 \pm 0.68$ points (Table 5).

\section{Comparison of health personnel's knowledge, at- titudes, and self-efficacy according to palliative care experience}

Differences in health personnel's knowledge, attitudes, and self-efficacy according to palliative care experience are presented in Table 6.

Fifty-seven participants (33.7\%) reported that they had received education related to palliative care, $94(55.6 \%)$ had been exposed to awareness-raising initiatives, 39 (23.1\%) had explained palliative care-related regulations or procedures, $29(17.2 \%)$ had provided patient or family counseling on the writing of advance directives or advance care planning, and 58 (34.3\%) had provided care for patients who had written advance directives or had advance care plans.

Participants who had received palliative care education had significantly higher scores for attitudes $(\mathrm{t}=-2.48, \mathrm{P}=0.015)$ and self-efficacy $(\mathrm{t}=-2.40, \mathrm{P}=0.017)$. Those who had been exposed to awareness-raising initiatives on palliative care had significantly higher scores for self-efficacy $(t=-2.31, \mathrm{P}=0.022)$. The level of knowledge about palliative care was significantly higher among those who were aware of advance directives $(\mathrm{t}=-2.42, \mathrm{P}=0.017)$.

Participants who had heard about advance care planning had a significantly higher level of knowledge $(\mathrm{t}=3.13 ; \mathrm{P}=0.002)$, attitudes $(t=2.22, P=0.027)$, and self-efficacy $(t=3.70 ; P$ $<0.001)$ than those who had not. Participants with experience in explaining palliative care-related regulations or procedures also had significantly higher levels of knowledge $(t=-3.77$, P $<0.001$ ), attitudes ( $t=-2.40 ; P=0.018)$, and self-efficacy ( $t=-$ $3.55, \mathrm{P}<0.001)$. Participants who had experience in consulting regarding making advance directives or advance care planning had significantly higher levels of knowledge $(t=-4.03$, P $<0.001)$ and self-efficacy $(t=-3.61, \mathrm{P}<0.001)$. Those who had experience in providing nursing care to patients or families who had advance directives or advance care plans had significantly higher levels of knowledge $(t=-2.84, \mathrm{P}=0.005)$ and selfefficacy $(\mathrm{t}=-4.17, \mathrm{P}<0.001)$.

\section{Correlations between health personnel's knowl- edge, attitudes, and self-efficacy related to pro- viding palliative care}

Health personnel's knowledge of palliative care was positively correlated with self-efficacy $(r=0.266, P<0.001)$, and attitudes were positively correlated with self-efficacy $(r=0.192$, $\mathrm{P}=0.012)$; however, the effect size was either weak or moderate (Table 7).

\section{DISCUSSION}

This study was conducted to help develop training programs for improving health personnel's knowledge, attitudes, and self-efficacy to meet the needs of patients with advanced chronic diseases other than cancer, who require palliative care that should be differentiated from hospice care for patients with terminal cancer, in the dying process, or at the end of life, thereby contributing to improving the quality of life for such patients [17].

Due to the absence of previous studies on advance care planning for patients with advanced chronic diseases, it is difficult to directly compare the findings of the current study on knowledge, attitudes, and self-efficacy according to sociodemographic characteristics with those of previous studies. However, when compared to similar studies involving nursing students [18] or intensive care unit nurses [19], it is noteworthy that the current study did not demonstrate significant dif-

Table 7. Correlations between Variables ( $N=169)$.

\begin{tabular}{|c|c|c|}
\hline \multirow{2}{*}{ Variables } & Knowledge & Attitudes \\
\hline & $r(P)$ & $r(P)$ \\
\hline Attitudes & $0.113(0.145)$ & \\
\hline Self-efficacy & $0.266(<0.001)$ & $0.192(0.012)$ \\
\hline
\end{tabular}


ferences in health personnel's knowledge of palliative care according to their age or career history. This may be attributable to the fact that the average age of the participants in this study was relatively high (34.2 years); furthermore, $88.8 \%$ of them had a 4-year college bachelor's degree or higher, and many of them had been exposed to awareness-raising initiatives at their institutions, which had been designated as pilot centers for palliative care, and this experience naturally contributed to the growth of their interest in palliative care.

In this study, the average score for health personnel's attitude toward palliative care was higher for participants with a longer career history or more personal experience (older age, married, having a child). In a similar vein, Jang et al. reported that more clinical experience as intensive care unit nurses and more personal experience were correlated with favorable attitudes toward palliative care provision [19]. The level of knowledge of advance care planning was higher among physicians than nurses, but their score for attitudes was lower than that of nurses. This may indicate the need to formulate a differentiated teaching-learning strategy for improving attitudes toward palliative care according to profession.

Health personnel were relatively well aware of life-sustaining treatment decisions as set forth by the recent law (77.5\%), but had a lower level of knowledge of advance care planning, which includes more comprehensive care decisions than those of advance directives (23.7\%). Since perceptions and needs of patients with advanced chronic diseases differ from those of cancer patients [16], health personnel should be prepared to provide proactive and comprehensive counseling for the patients regarding advance care planning. Furthermore, the training program should include legal aspects about advance care planning.

Low scores for communications with patients/family and the interdisciplinary team, as well as bioethics, indicate the content areas that training for health personnel should focus on in the future. Empathetic communication skills to provide patients and family the right amount of information to make shared decisions are essential to support and protect patients' dignity and rights. Therefore, it is necessary to develop a training program for health personnel to improve communication confidence and skills to deliver bad news and to discuss advance care planning. Furthermore, clearer expectations of roles and responsibilities based on professional and cultural expectations should be established to prevent conflicts and dilemmas, as Lee et al. pointed out [18]. Narrative education or role playing would be good candidates for training to enhance the capacity of health personnel to make shared decisions with patients and communicate with multidisciplinary team members.

A smaller number of participants had experienced explaining (23.1\%) or consulting (17.2\%) about life-sustaining treatment policies or procedures than had treated or provided nursing care for patients and their families (34.3\%) who had made advance directives or had advance care plans. This may provide evidence that death with dignity and life-sustaining treatment have become relatively familiar concepts, as interest in bioethics has increased, and more patients and their families have accepted palliative care as a treatment option, whereas health personnel have not been properly trained to provide these services. In addition, professional and environmental constraints associated with clinical practice may hinder health personnel from fulfilling their full potential. Prior studies have pointed out that health personnel's competency in providing palliative care can be improved through training [7,17]. The United Kingdom has provided education on palliative care for undergraduates in medicine and nursing for over 20 years [20]. The United States has also recently paid more attention to education on palliative care for health personnel [21]. It is time for Korea to consider expanding education related to palliative care in schools, as well as continuing education for health personnel.

Experience in providing palliative care is directly related to the attitudes of health personnel (especially primary care providers), the knowledge of palliative care and methodological issues (policy, regulations or procedures). According to a prior study by Shin et al. [6], physicians treating patients with chronic diseases agreed that palliative care should be provided to patients with chronic diseases, but as they equated palliative care with hospice care, they did not express consensus regarding when to provide palliative care, how to initiate discussions on life-sustaining treatment, or what to discuss. This suggests the need to provide practical guidance regarding when health personnel should offer which forms of specific palliative care to patients with chronic diseases and offer training on how to practice palliative care in clinical settings. 
Regarding the correlations between health personnel's knowledge, attitudes, and self-efficacy related to palliative care, the correlation between knowledge and self-efficacy was stronger than that between attitudes and self-efficacy, but both knowledge and attitudes showed positive correlations with self-efficacy. Carper [22] reported that nursing knowledge (the ways of knowing) is improved via personal, empirical, ethical, and aesthetic knowing; this premise can be applied not only to nurses, but also to all health personnel who need to provide patient-centered care. When empirical knowing is extended through aesthetic and personal knowing and the ethical anguish as human beings is resolved through reflection and training, health personnel will have more empathetic attitudes and improved self-efficacy for providing palliative care.

Based on the above findings, we would like to suggest palliative care directions for patients with advanced chronic diseases. First, prior studies emphasized that advance care planning for patients with chronic diseases should be done in the early stage of the disease, not the end stage [7,23]. In addition, the palliative care services expected from patients with chronic diseases encompass not only the decisions related to life-sustaining treatment required by law (only four life-sustaining treatments were specified as available for patients to decide upon in 2018, at the time of the study), but also more comprehensive medical treatment decisions and even non-medical care services, which can improve the quality of life of both patients and their families $[2,11,24]$. Thus, palliative care for patients with chronic diseases should be planned and provided with consideration of these needs. Second, according to prior research, health personnel's attitudes toward palliative care depend on their perspectives regarding a desirable life and death, personal values, culture, norms, and laws [17,25]. For successful implementation, it is necessary to go beyond simply introducing services that originated from different cultures and backgrounds; instead, it is necessary to develop palliative care services tailored to the specific cultural setting and target patient characteristics $[11,16]$. Furthermore, since successful palliative care requires a team-based approach, inter-professional training should be planned and offered.

Notwithstanding the significance of our findings, the current study has the following limitations. First, advance care planning for patients with advanced chronic diseases may need to include not only medical treatment decisions, but also nonmedical services such as care coordination to use community resources to meet the needs of patients and family [11]. Since this study was a pioneering study, it was difficult to find reliable and valid research tools to assess the needs of care coordination. Therefore, it is necessary to conduct followup research focusing on tool development after a study with concept analysis or Q-methodology to identify perceptions and needs regarding palliative care and care coordination in patients with chronic diseases [26]. Second, it is necessary to examine whether non-medical health professionals such as social workers are prepared to provide palliative care to meet the needs of patients with advanced chronic diseases. Finally, since this study was conducted at a tertiary hospital, the results need to be carefully interpreted, and replication with a larger sample size is warranted.

\section{CONFLICT OF INTEREST}

No potential conflict of interest relevant to this article was reported.

\section{ORCID}

EunSeok Cha, https://orcid.org/0000-0001-6115-567X

Sojung Lee, https://orcid.org/0000-0002-0057-4114

Jooseon Lee, https://orcid.org/0000-0001-8839-3264

Insil Lee, https://orcid.org/0000-0001-5941-1363

\section{AUTHOR'S CONTRIBUTIONS}

Conceptualization or design of the work: ESC. Data collection: JL. Formal analysis: SL. Data interpretation: ESC, SL, IL. Manuscript writing: ESC, SL. Critical revision of the article: IL, JL.

\section{SUPPLEMENTARY MATERIALS}

Supplementary materials can be found via https://doi. org/10.14475/kjhpc.2020.23.4.198. 


\section{REFERENCES}

1. Choi KS. Issues and tasks in the hospice, palliative care, and life-sustaining treatment decision-making act. Korean J Med Ethics 2016;19:121-40.

2. Ahia CL, Blais CM. Primary palliative care for the general internist: integrating goals of care discussions into the outpatient setting. Ochsner J 2014;14:704-11.

3. von Gunten CF. Secondary and tertiary palliative care in US hospitals. JAMA 2002;287:875-81.

4. Block SD, Bernier GM, Crawley LM, Farber S, Kuhl D, Nelson W, et al. Incorporating palliative care into primary care education. National Consensus Conference on Medical Education for Care Near the End of Life. J Gen Intern Med 1998;13:768-73.

5. Billings JA. What is palliative care? J Palliat Med 1998;1:73-81.

6. Shin J, Yoon SJ, Kim SH, Lee ES, Koh SJ, Park J. A qualitative study of physicians' perspectives on non-cancer hospice-palliative care in Korea: focus on AIDS, COPD and liver cirrhosis. Korean J Hosp Palliat Care 2017;20:177-87.

7. de Caprariis PJ, Rucker B, Lyon C. Discussing advance care planning and directives in the general population. South Med J 2017;110:563-8.

8. Chun SY. The modern way of understanding and communication of death: In case of medical institutions. Korean J Sociol 2003;37:171-99.

9. Jo KH, Kim GM. Health personnel's comprehension of death in Korea. Korean J Med Ethics 2013;16:124-38

10. Korea National Institue for Bioethics Policy. 2019 Annual report for life-sustaining decision making system. Seoul:Korea National Institue for Bioethics Policy;2020. p. 17-55.

11. Cha ES, Lee J, Lee K, Hwang Y. Illness experiences and palliative care needs in community dwelling persons with cardiometabolic diseases. Korean J Hosp Palliat Care 2019;22:8-18.

12. Polit DF, Beck CT, Owen SV. Is the CVI an acceptable indicator of content validity? Appraisal and recommendations. Res Nurs Health 2007;30:459-67.

13. Jezewski MA, Brown JK, Wu YWB, Meeker MA, Feng JY, Bu X. Oncology nurses' knowledge, attitudes, and experiences regarding advance directives. Oncol Nurs forum 2005;32:319-27.

14. Kim MY, Kim KS. Korean nurses' attitude towards advance directives and end of life decision making. J Korean Crit Care Nurs 2010;3:77-90.

15. Hong SW, Kim SM. Knowledge regarding advance directives among community-dwelling elderly. J Korean Acad Soc Nurs Educ 2013;19:330-40.

16. Cha E, Kim J, Sohn M, Lee BS, Jung SS, Lee SJ, et al. Perceptions on good-life, good-death, and advance care planning in Koreans with noncancerous chronic diseases. J Adv Nurs. In press.

17. Chan $\mathrm{CWH}, \mathrm{Ng} \mathrm{NHY}$, Chan HYL, Wong MMH, Chow KM. A systematic review of the effects of advance care planning facilitators training programs. BMC Health Serv Res 2019;19:362.

18. Lee HJ, Ha JH, Yun J. Nursing students' knowledge, attitudes to advance medical directives and ethics values. J Korean Acad Nurs Adm 2019;25:282-91.

19. Jang NS, Park HS, Kim MR, Lee JY, Cho YW, Kim KM, et al. Knowledge, confidence, and learning needs regarding advance directives among hospital nurses. J Korean Crit Care Nurs 2018;11:35-45.

20. Lloyd-Williams M, Carter YH. In search of a good death: Medical education has important role in extending palliative care. BMJ 2003;327:221-2.

21. Radhakrishnan K, Saxena S, Jillapalli R, Jang Y, Kim M. Barriers to and facilitators of south asian indian-americans' engagement in advanced care planning behaviors. J Nurs Scholarsh 2017;49:294-302.

22. Carper B. Fundamental patterns of knowing in nursing. ANS Adv Nurs Sci 1978;1:13-23.

23. Howard M, Bernard C, Tan A, Slaven M, Klein D, Heyland DK. Advance care planning: Let's start sooner. Can Fam Physician 2015;61:663-5.

24. Hattori K, McCubbin MA, Ishida DN. Concept analysis of good death in the Japanese community. J Nurs Scholarsh 2006;38:165-70.

25. Ke LS, Huang X, O'Connor M, Lee S. Nurses' views regarding implementing advance care planning for older people: a systematic review and synthesis of qualitative studies. J Clin Nurs 2015;24:2057-73.

26. Zabala A. qmethod: A Package to Explore Human Perspectives Using Q Methodology. The R Journal 2014;6:163-73. 